\title{
Comparisons of mortality and pre-discharge respiratory outcomes in small-for-gestational-age and appropriate-for-gestational-age premature infants
}

\author{
Puneet Sharma ${ }^{1}$, Kathleen McKay ${ }^{2}$, Ted S Rosenkrantz ${ }^{1}$ and \\ Naveed Hussain*1
}

Address: ${ }^{1}$ Department of Pediatrics, Division of Neonatology, University of Connecticut Health Center, 263 Farmington Avenue, Farmington, CT 06030-2948, USA and 2Research Division, Child Health Data Center, Connecticut Children's Medical Center, 282 Washington Street, Hartford, CT 06106, USA

Email: Puneet Sharma - punsharma@hotmail.com; Kathleen McKay - kmckay@ccmckids.org; Ted S Rosenkrantz - rosenkrant@nso1.uchc.edu; Naveed Hussain* - hussain@nso1.uchc.edu

* Corresponding author

Published: 08 June 2004

BMC Pediatrics 2004, 4:9
Received: 22 December 2003

Accepted: 08 June 2004

This article is available from: http://www.biomedcentral.com/|47I-243I/4/9

(C) 2004 Sharma et al; licensee BioMed Central Ltd. This is an Open Access article: verbatim copying and redistribution of this article are permitted in all media for any purpose, provided this notice is preserved along with the article's original URL.

\begin{abstract}
Background: There are differences in the literature regarding outcomes of premature small-for-gestational-age (SGA) and appropriate-for gestational-age (AGA) infants, possibly due to failure to take into account gestational age at birth.

Objective: To compare mortality and respiratory morbidity of SGA and AGA premature newborn infants.

Design/Methods: A retrospective study was done of the 2,487 infants born without congenital anomalies at $\leq 36$ weeks of gestation and admitted to the neonatal intensive care unit (NICU) at John Dempsey Hospital, between Jan. 1992 and Dec. 1999. Recent (1994-96) U.S. birth weight percentiles for gestational age (GA), race and gender were used to classify neonates as SGA ( $<10$ th percentile for GA) or AGA (10th-90th percentile for GA). Using multivariate logistic regression and survival analyses to control for GA, SGA and AGA infants were compared for mortality and respiratory morbidity.
\end{abstract}

Results: Controlling for GA, premature SGA infants were at a higher risk for mortality (Odds ratio 3.I, $\mathrm{P}=$ $0.00 \mathrm{I})$ and at lower risk of respiratory distress syndrome $(O R=0.7 \mathrm{I}, \mathrm{P}=0.02)$ than AGA infants. However multivariate logistic regression modeling found that the odds of having respiratory distress syndrome (RDS) varied between SGA and AGA infants by GA. There was no change in RDS risk in SGA infants at GA $\leq 32$ wk $(\mathrm{OR}=1.27,95 \% \mathrm{Cl} 0.32-1.98)$ but significantly decreased risk for $\mathrm{RDS}$ at $\mathrm{GA}>32 \mathrm{wk}(\mathrm{OR}=0.4 \mathrm{I}, 95 \% \mathrm{Cl} 0.27$ $-0.63 ; p<0.01$ ). After controlling for GA, SGA infants were observed to be at a significantly higher risk for developing chronic lung disease as compared to $A G A$ infants $(O R=2.2,95 \% \mathrm{Cl}=1.2-3.9, P=0.01$ ). There was no significant difference between SGA and AGA infants in total days on ventilator. Among infants who survived, mean length of hospital stay was significantly higher in SGA infants born between 26-36 wks GA than AGA infants.

Conclusions: Premature SGA infants have significantly higher mortality, significantly higher risk of developing chronic lung disease and longer hospital stay as compared to premature AGA infants. Even the reduced risk of RDS in infants born at $\geq 32$ wk GA, (conferred possibly by intra-uterine stress leading to accelerated lung maturation) appears to be of transient effect and is counterbalanced by adverse effects of poor intrauterine growth on long term pulmonary outcomes such as chronic lung disease. 


\section{Background}

Small for gestational age infants (SGA) represent a significant percentage of infants admitted to the Neonatal Intensive care units (NICU). There are a number of studies comparing premature small for gestational age (SGA) infants with appropriate for gestational age (AGA) infants, for differences in their mortality and morbidity [1-8] Although there is a consensus that premature SGA infants have higher mortality than AGA infants, the differences in outcomes regarding respiratory and non-respiratory morbidity are controversial. The discrepancies between different studies may partly be explained by variations in gestational age (GA) of the study populations and by the studies' failure to stratify the study population by GA. Moreover, several of these studies used birth weight percentile curves from older norms, to determine whether the infant is SGA or AGA [9-11] and/or did not take into account the racial differences in birth weight.

The aim of the present study was to compare the respiratory outcomes between premature SGA and AGA infants stratified by gestational age, using the most current US birth weight percentiles for gestational age by race and gender. [12]

\section{Methods}

This is a retrospective study involving 2,530 infants born at $\leq 36$ weeks of gestational age and admitted to the NICU at University Of Connecticut Health Center, Farmington, CT, between January 1992 and December 1999. Fortythree infants born with congenital malformations or chromosomal aberrations were excluded from the study and the remaining 2,487 infants were included in the analyses.

Gestational age was determined based on maternal menstrual history and early fetal ultrasound. If, rarely, a difference of more than 2 weeks was observed using the physical exam based modified Ballard score, then the newly assessed GA was used. [13]Infants were classified as SGA $\left(<10^{\text {th }}\right.$ percentile for gestational age), AGA $\left(10^{\text {th }}\right.$ to $90^{\text {th }}$ percentile for gestational age) and LGA (Large for gestational age) ( $>90^{\text {th }}$ percentile for gestational age) based on US singleton birth weight percentiles for gestational age by race and gender. [12]Mortality was based on death prior to hospital discharge. Respiratory Distress Syndrome was diagnosed on the basis of clinical presentation and chest radiographs. [14] Long-term morbidity (Days on ventilator, BPD, Chronic lung disease and length of hospital stay) was studied only for the infants who survived $\geq 28$ days of life. Days on Ventilator included total number of days on Bear 750 servo controlled ventilator, Sensor medics 3100 A High-frequency oscillator and/or Continuous Positive Airway Pressure. BPD was diagnosed based upon need for any amount of supplemental oxygen at 28 days of life. Chronic lung disease was based upon any sup- plemental oxygen need at 36 weeks postmenstrual age [GA at birth (wks) plus weeks after birth]. Length of hospital stay included total number of days that the infant was in the NICU before being discharged. The infants were discharged when they were at $\geq 35$ weeks of postmenstrual age, able to maintain body temperature in open crib, free of apneic spells for $\geq 7$ days and on full oral feeds. Infants who were transferred to another hospital were included and constituted $<10 \%$ of the group.

\section{Statistics}

Univariate analyses, multivariate logistic regression analyses and survival analyses were performed and odds ratio with 95\% confidence intervals were calculated for the major outcome variables. $P$ value $\leq 0.05$ was considered to be statistically significant.

\section{Results \\ Patient demographics}

Of the 2,487 neonates included in the study, 358 (14.4\%) were classified as SGA, 2,008 (80.7\%) were classified as AGA, 41 (1.6\%) were classified as LGA and 80 (3.3\%) could not be classified for incomplete data. The distributions of GA, birth weight, sex and race distribution along with maternal factors are shown in table 1 . Table 2 shows distribution of population based on groups classified by GA at birth (wk).

Table I: Distribution of study population based on gender and ethnicity

\begin{tabular}{|c|c|c|}
\hline & SGA $(n=358)$ & AGA $(n=2008)$ \\
\hline Gestational Age (wks) & $33.2 \pm 2.5$ & $30.9 \pm 3.5$ \\
\hline Birth weight (gm) & $1524.6 \pm 466$ & $1753.5 \pm 683$ \\
\hline Male Sex & 197 (55\%) & $109(55 \%)$ \\
\hline \multicolumn{3}{|l|}{ Race } \\
\hline Whites & $270(75 \%)$ & $1620(81 \%)$ \\
\hline African-Americans & $42(12 \%)$ & $192(9 \%)$ \\
\hline Hispanics & $46(13 \%)$ & $196(10 \%)$ \\
\hline Maternal HTN & $8(2.3 \%)^{\mathrm{a}}$ & $5 \mathrm{I}(2.6 \%)^{\mathrm{b}}$ \\
\hline Antepartum Bleeding & $59(16.8 \%)^{a}$ & $389(19.7 \%)^{b}$ \\
\hline Chorioamnionitis & $70(19.9 \%)^{\mathrm{a}}$ & $315(16.0 \%)^{b}$ \\
\hline
\end{tabular}

Data shown as frequency (\%) or mean $\pm \mathrm{sd}$ a - missing data on 7 infants, $b$ - missing data on 37 infants

\section{Mortality}

The relationship of mortality between SGA and AGA premature infants, stratified by GA, is shown in the figure 1 . Controlling for GA, logistic regression analysis showed that premature SGA neonates were at a higher risk of mortality than premature AGA infants (Odds Ratio 3.1, p = $0.001)$. Among the 15 SGA infants who died 12 had RDS (80\%), 5 developed pulmonary hemorrhage (33\%), 2 suffered from perinatal asphyxia (13\%), 2 developed sepsis 
Table 2: Distribution of study population based on gestational age

\begin{tabular}{ccc}
\hline GA & SGA $(\mathbf{n}=\mathbf{3 5 8})$ & AGA $(\mathbf{n}=\mathbf{2 0 0 8})$ \\
\hline 22-25 weeks & $8(2.2 \%)$ & $167(10.4 \%)$ \\
26-28 weeks & $11(3.1 \%)$ & $312(15.5 \%)$ \\
29-3 I weeks & $46(12.8 \%)$ & $447(22.3 \%)$ \\
32-34 weeks & $161(45 \%)$ & $731(36.4 \%)$ \\
35-36 weeks & $132(36.9 \%)$ & $307(15.3 \%)$ \\
\hline
\end{tabular}

Data shown as frequency (\%)

(13\%) and 1 infant each developed intraventricular hemorrhage and pneumothorax (6.7\%); an infant may have had more than one diagnosis. Among the 117 AGA infants who died 101 developed RDS (86.3\%), 24 had pulmonary hemorrhage (20.5\%), 5 suffered from perinatal asphyxia (4.3\%), 26 had sepsis $(22.2 \%), 31$ developed IVH (26.5\%) and 34 developed pneumothorax (29.1\%). Among infants who died, the age of death was similar for SGA and AGA infants (SGA vs. AGA, mean \pm sd; $17.1 \pm$ 41.4 days vs. $14.3 \pm 32.9$ days, $\mathrm{p}=0.6$ ).

\section{Respiratory distress syndrome}

The relationship of RDS between SGA and AGA premature infants is shown in the figure 2. Controlling for GA, multivariate logistic regression analysis showed that premature SGA infants are at a lower risk for RDS than premature AGA infants (Odds ratio $=0.71,95 \% \mathrm{CI}=0.53$ - 0.94; $\mathrm{P}=0.02)$. As shown in table 3 , at the lower gestational age groups (24 - 31 weeks), the incidence of RDS was not significantly different between the two groups. At GA 32-34 weeks, SGA infants were observed to be at a lower risk for having RDS and this difference approached significance $(\mathrm{p}=0.09)$. However at GA $>34$ weeks, the incidence of RDS in SGA infants was significantly lower than AGA infants $(\mathrm{p}<0.002)$. Overall, there was no change in RDS risk in SGA infants at GA $\leq 32$ wk $(\mathrm{OR}=$ $1.27,95 \%$ CI $0.32-1.98$ ) but significantly decreased risk for RDS at GA > $32 \mathrm{wk}(\mathrm{OR}=0.41,95 \% \mathrm{CI} 0.27-0.63$; $<0.01)$.

\section{Days on ventilator}

After controlling for GA, among the SGA and AGA infants who survived till discharge, there was no significant difference in the number of days on ventilator $(R R=0.94,95 \%$ $\mathrm{CI}=0.87-1.02 ; \mathrm{P}=0.13$ ).

\section{Broncho-pulmonary dysplasia}

After controlling for GA, among infants who survived until 28 days of life, SGA infants were observed to be at a slightly higher risk for developing BPD. This difference was not significant statistically (OR $=1.09,95 \% \mathrm{CI}=0.64$ - 1.8; $\mathrm{P}=0.73$ ).

\section{Chronic lung disease (defined as continuing need for supplemental oxygen at $36 \mathrm{wk}$ corrected age)}

After controlling for GA, among infants who survived until 28 days of life, SGA infants were observed to be at a significantly higher risk for developing chronic lung disease as compared to AGA infants $(\mathrm{OR}=2.2,95 \% \mathrm{CI}=1.2$ $-3.9 ; \mathrm{P}=0.01)$.

\section{Length of hospital stay}

Among the infants who survived till discharge from the hospital, SGA infants had a significantly longer hospital stay than AGA infants (RR 1.29, 95\% CI $=1.22-1.37$, P $<0.0001)$. The relationship of length of hospital stay between SGA and AGA premature infants, stratified by GA, is shown in the Figure 3 and Table 4.

\section{Discussion}

It is a commonly held assumption that growth restricted fetuses are "stressed" by unfavourable in-utero environment and have accelerated lung maturation and thus lower incidence of pulmonary complications when compared to appropriately grown infants. $[15,16]$ However different studies have conflicting reports on outcomes of premature SGA infants when compared to premature AGA infants with some reporting an increased mortality and morbidity $[1,3,4,7,8]$, some reporting decreased [5] and some reporting no change in the mortality and morbidity of SGA preterm infants when compared to AGA infants. [17-19]

Regarding mortality, our study confirmed that premature SGA neonates were at a higher risk of mortality than premature AGA infants (Odds Ratio 3.1, p = 0.001) and most of the risk of mortality was in the lower gestational age groups (23-31 weeks) as shown in the figure 1. These findings are consistent with those observed in some of the previous studies $[3,8,20-22]$. One study by Bardin et al [1] however did not observe any significant difference in mortality between the two groups. This study's population however was limited to $24-26$ weeks of GA with only 41 SGA infants enrolled and did not represent the complete spectrum of premature infants. A recent report from Lal et al from a geographically defined population has confirmed that SGA preterm infants are at higher risk for chronic lung disease and death before 28 days of birth and 36 weeks post-menstrual age. [23]

In our study, the premature SGA infants were observed to be at a lower risk for RDS than premature AGA infants (Odds ratio $=0.71, \mathrm{P}=0.02$ ). Procianoy et al [5] had also shown the incidence of RDS to be lower in SGA infants as compared to AGA infants born $\leq 32$ weeks of GA. However other studies have found either no difference between the two groups $[1,3,8]$ or an increased incidence and severity of RDS in premature SGA infants $[7,24]$. The concept of 


\section{Mortality in AGA and SGA infants}

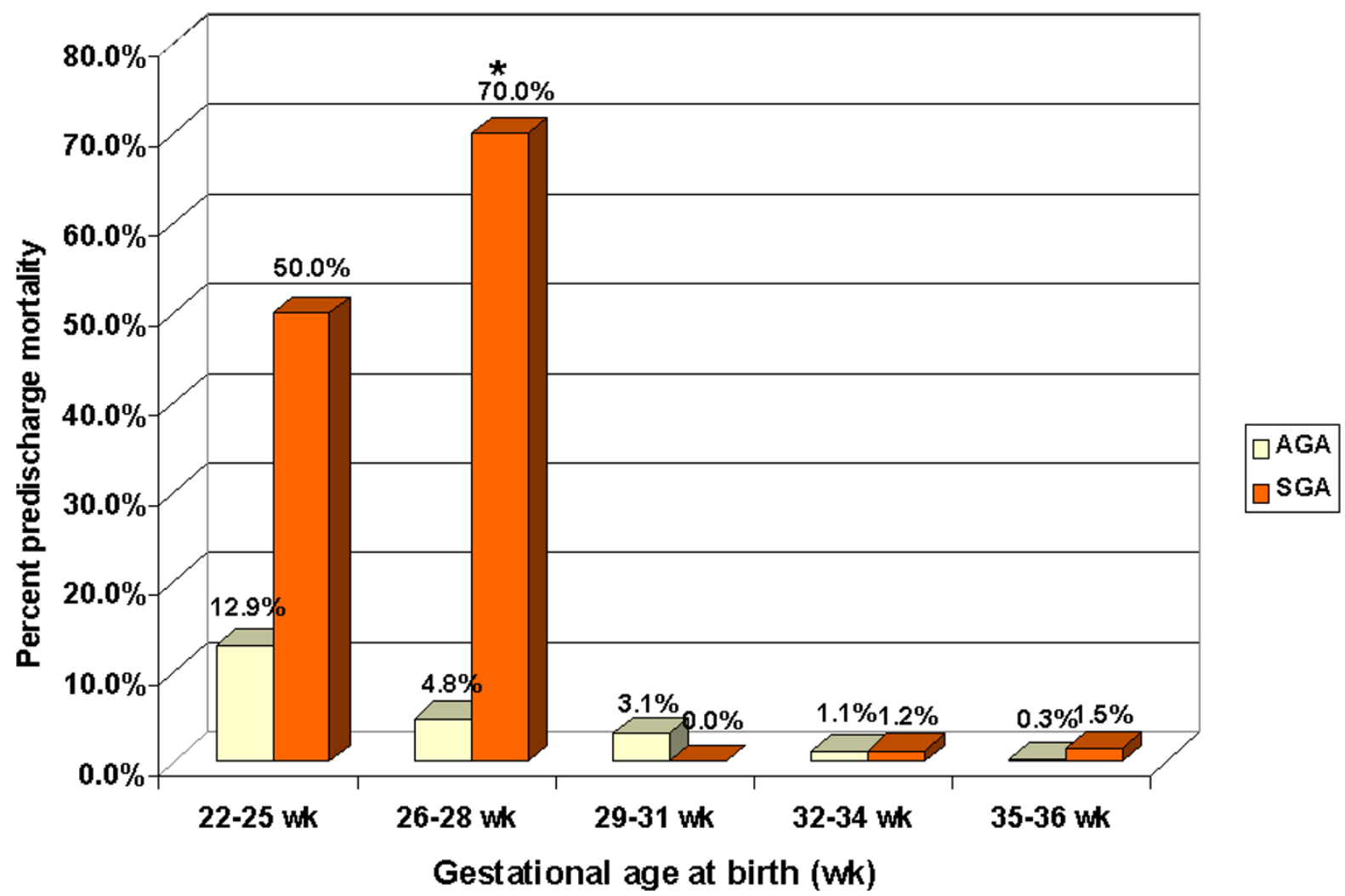

\section{Figure I}

Mortality by gestational age The figure represents percent of infants that died in each gestational age group. AGA infants are represented by the lighter bars and SGA infants are represented by the darker bars.

accelerated lung maturation in response to stress was initially proposed in 1980s [16]. The concept was supported by data demonstrating improved biochemical pulmonary profile in growth restricted babies $[25,26]$. However postulated benefits of accelerated lung maturation may be counterbalanced by fetal hypoxemia and acidosis secondary to decreased utero-placental perfusion [27]. In our population, there appears to be is a distinct GA (>32 wks) where this balance appears to be shifted in favor of accelerated lung maturation and lower incidence of RDS (Figure 2).

The analysis for days on ventilator represents the severity of initial lung disease. From our study it is clear that despite the lower incidence of RDS in SGA infants as com- pared to AGA infants, the total number of days on ventilator in both groups is not different suggesting that the advantage of "stressed" lung is transient.

We found that SGA infants were at a slightly higher risk for developing BPD and at a significantly higher risk of developing chronic lung disease defined at 36 wk post-menstrual age. These findings are consistent with previous studies $[1,3,28,29]$ which showed premature SGA infants to have increased incidence of BPD and/or chronic lung disease. It needs to be emphasized that the stratification by GA of these outcomes had not been done in these earlier studies and some were limited in the population studied, by GA $\leq 32 \mathrm{wk}$ [28] or by birth weight $\leq 1500 \mathrm{gm}$ [29]. Etiology of chronic lung disease is multifactorial, with var- 


\section{Incidence of RDS by gestational age at birth}

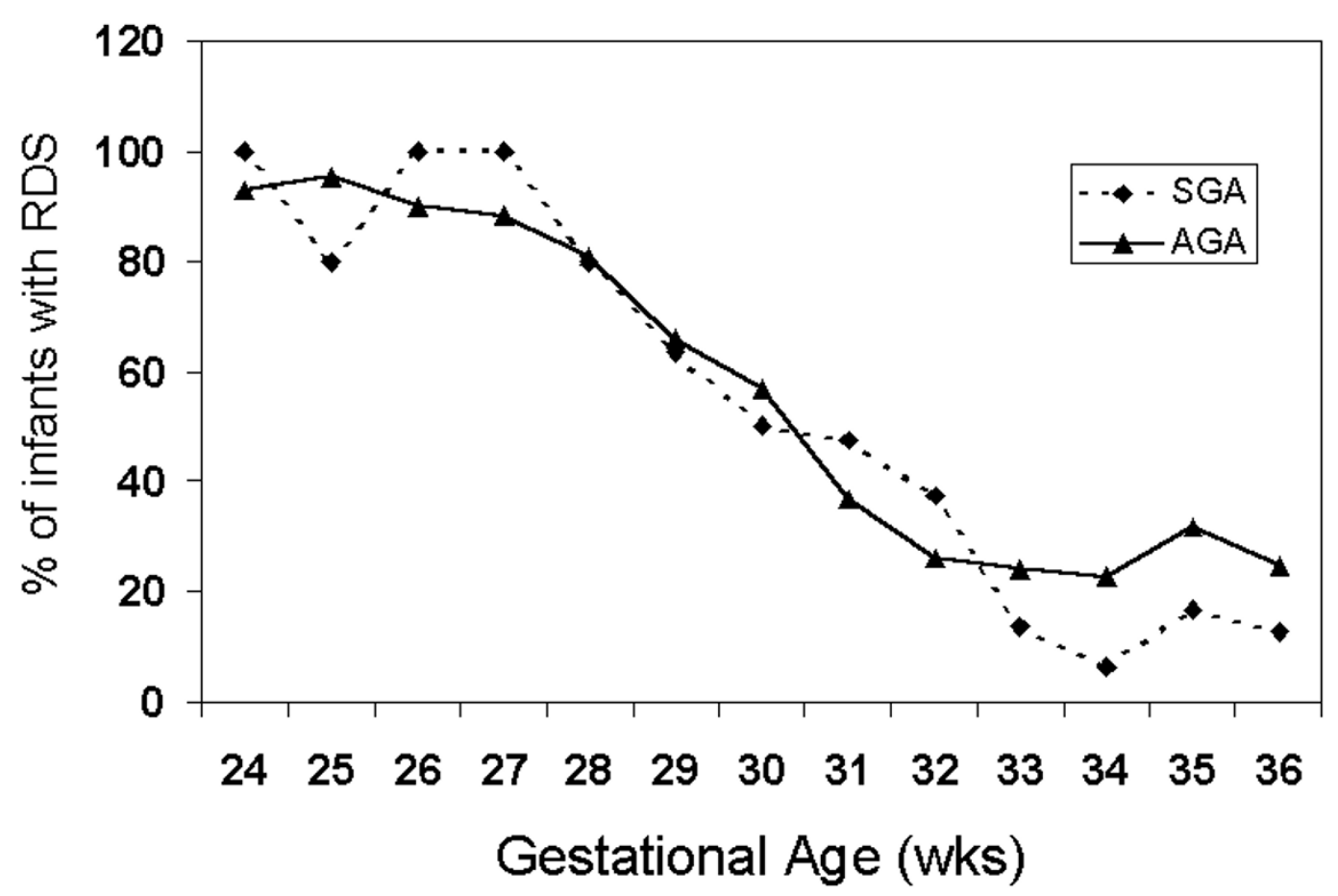

Figure 2

RDS by gestational age The figure represents percent of infants who developed RDS at each gestational age. SGA infants are represented by dotted line and AGA infants are represented by continuous line.

Table 3: Odds of RDS in SGA/AGA infants

\begin{tabular}{llll}
\hline GA groups & Odds ratio & $\mathbf{9 5 \%} \mathbf{C l}$ & P Value \\
\hline 22-25 wks & 0.38 & $0.06-7.6$ & 0.44 \\
26-28 wks & 1.55 & $0.28-29$ & 0.66 \\
29-3 I wks & 0.99 & $0.54-1.83$ & 0.98 \\
32-34 wks & 0.62 & $0.44-1.06$ & 0.09 \\
35-36 wks & 0.45 & $0.25-0.73$ & $0.002^{*}$ \\
\hline
\end{tabular}

* Statistically significant

ious factors such as RDS, duration and degree of ventilator support, higher oxygen concentration exposure of the infant and chronic malnutrition, playing significant roles. Chronic undernutrition, as in case of intrauterine growth retardation, can aggravate the deficiency of antioxidants which might predispose the infant to chronic lung disease or make it worse [30]. Moreover, pulmonary alveolarization has been shown to be reduced by nutritional deprivation in experimental animals [31]. The hypoxemia and acidosis experienced by the fetus due to factors that induce restricted growth may be involved in the release of pro-inflammatory factors like Tumor Necrosis Factoralpha [32]. Fetal exposure to Tumor Necrosis Factor-alpha has been shown to increase RDS and chronic lung disease in infants $[33,34]$.

Length of hospital stay reflects severity of illness and morbidity among survivors. Our study showed that the SGA infants had a significantly longer hospital stay than AGA infants. This is consistent with observation made in other studies [1-3] and can be explained by increased complexity and severity of medical problems faced by premature SGA infants as compared to AGA infants. 


\section{Length of hospital stay}

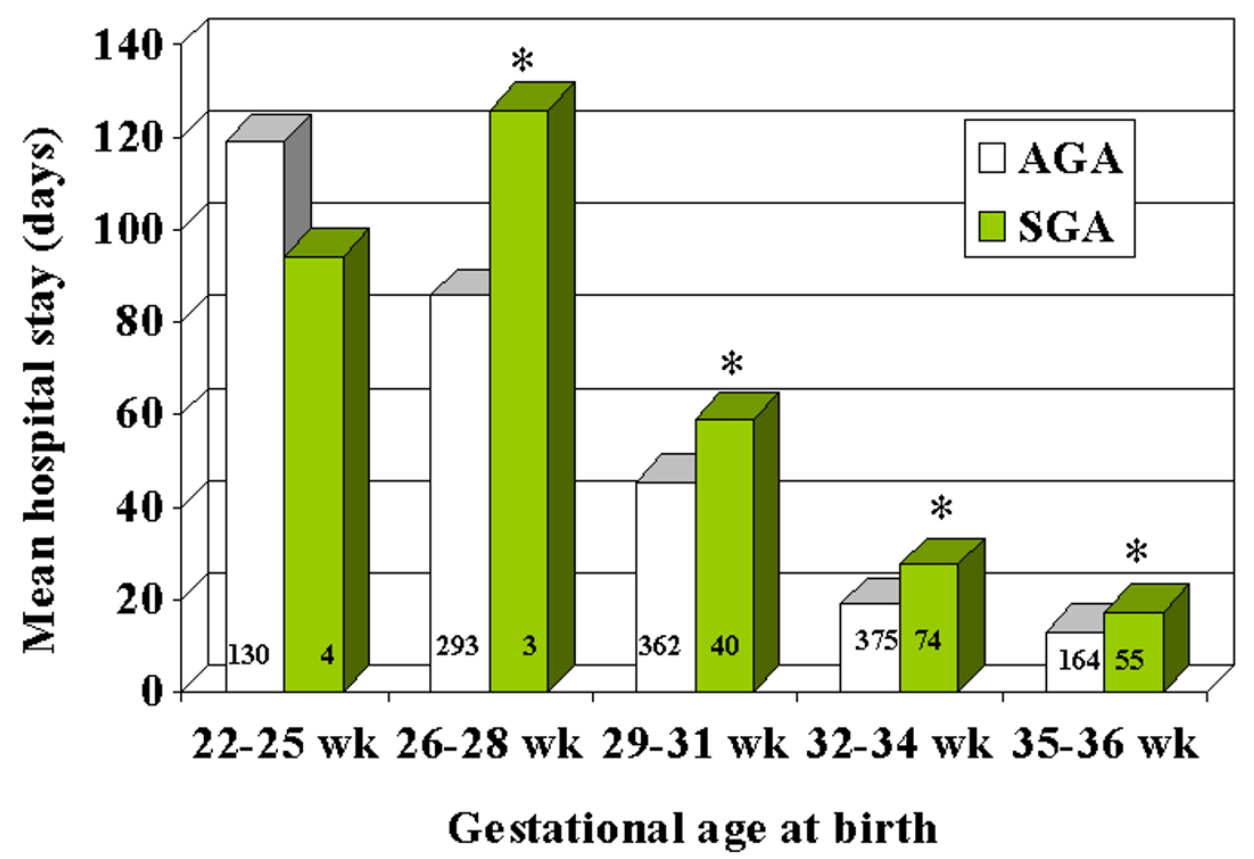

Figure 3

Length of hospital stay The figure represents the total length of stay in the hospital among infants who survived to 28 days. AGA infants are represented by the lighter bars and SGA infants are represented by darker bars. Total numbers of infants in each gestational age group are shown within the bars. $*$ indicates $p<0.05$.

Table 4: Relative risk of length of hospital stay in SGA/AGA infants

\begin{tabular}{llll}
\hline GA groups & Relative Risk & $\mathbf{9 5 \%} \mathbf{C l}$ & P Value \\
\hline 22-25 wks & 0.98 & $0.64-1.78$ & 0.95 \\
$\mathbf{2 6 - 2 8}$ wks & 1.77 & $1.09-3.57$ & $0.02^{*}$ \\
$\mathbf{2 9 - 3 1}$ wks & 1.28 & $1.1-1.5$ & $0.0008^{*}$ \\
$\mathbf{3 2 - 3 4}$ wks & 1.35 & $0.24-1.47$ & $<0.0001^{*}$ \\
$\mathbf{3 5 - 3 6}$ wks & 1.21 & $1.1-1.35$ & $0.0002^{*}$
\end{tabular}

* Statistically significant

\section{Conclusions}

In conclusion, our study showed that when compared to premature AGA infants, premature SGA infants have significantly higher risk of mortality, significantly lower risk of RDS (though most of this benefit appears to be at GA 32-36 wks), significantly higher risk of developing chronic lung disease and a significantly longer hospital stay.

This study is unique in that it has utilized newer United States gender and race specific norms to classify infants as SGA and AGA. Also of note is that the lower incidence of RDS in SGA infants was observed to be most significant at the gestational ages $32-36 \mathrm{wks}$, but not at $<32 \mathrm{wks}$, this may partly explain the discrepancies observed with some of the previous studies which studied premature infants as a single group and/or failed to look at the outcomes at different gestational ages. Transient benefit of accelerated lung maturity in premature SGA infants, as seen by lower incidence of RDS, does not appear to influence other pulmonary outcomes such as days on ventilator and BPD. On the other hand compromised nutrition [30] and intrauterine growth appears to play a more important role in determining long-term pulmonary morbidity such as chronic lung disease. 


\section{Competing interests}

None declared.

\section{Abbreviations}

GA, gestational age;

SGA, Small for gestational age;

AGA, Appropriate for gestational age;

RDS, respiratory distress syndrome,

BPD, bronchopulmonary dysplasia;

CLD, chronic lung disease;

\section{Acknowledgements}

The authors would like to thank Marta Baker, MSN, and Barbara Westman for their invaluable help with data collection and retrieval.

\section{References}

I. Bardin C, Zelkowitz P, Papageorgiou A: Outcome of small-forgestational age and appropriate-for-gestational age infants born before 27 weeks of gestation. Pediatrics 1997, I00:E4.

2. Ott WJ: Small for gestational age fetus and neonatal outcome: reevaluation of the relationship. Am J Perinatol 1995, I 2:396-400.

3. Gortner L, Wauer RR, Stock GJ, Reiter HL, Reiss I, Jorch G, Hentschel R, Hieronimi G: Neonatal outcome in small for gestational age infants: do they really better? J Perinat Med I999, 27:484-489.

4. Piper JM, Xenakis EM, McFarland M, Elliott BD, Berkus MD, Langer O: Do growth-retarded premature infants have different rates of perinatal morbidity and mortality than appropriately grown premature infants? Obstet Gynecol 1996, 87: I69-I74.

5. Procianoy RS, Garcia-Prats JA, Adams JM, Silvers A, Rudolph AJ: Hyaline membrane disease and intraventricular haemorrhage in small for gestational age infants. Arch Dis Child 1980, 55:502-505.

6. Ruys-Dudok van Heel I, de Leeuw R: Clinical outcome of small for gestational age preterm infants. J Perinat Med 1989, | 7:77-83.

7. Tyson JE, Kennedy K, Broyles S, Rosenfeld CR: The small for gestational age infant: accelerated or delayed pulmonary maturation? Increased or decreased survival? Pediatrics 1995, 95:534-538.

8. Simchen MJ, Beiner ME, Strauss-Liviathan N, Dulitzky M, Kuint J, Mashiach S, Schiff E: Neonatal outcome in growth-restricted versus appropriately grown preterm infants. Am J Perinatol 2000, 17:187-192.

9. Battaglia FC, Lubchenco LO: A practical classification of newborn infants by weight and gestational age. J Pediatr 1967, 71:159-163.

10. Usher R, McLean F: Intrauterine growth of live-born Caucasian infants at sea level: standards obtained from measurements in 7 dimensions of infants born between 25 and 44 weeks of gestation. J Pediatr 1969, 74:901-910.

II. Lubchenco LO: Assessment of gestational age and development of birth. Pediatr Clin North Am 1970, I 7: | 25-| 45.

12. Alexander GR, Kogan MD, Himes JH: I994-I996 U.S. singleton birth weight percentiles for gestational age by race, Hispanic origin, and gender. Matern Child Health J I999, 3:225-23I.

13. Ballard JL, Khoury JC, Wedig K, Wang L, Eilers-Walsman BL, Lipp R: New Ballard Score, expanded to include extremely premature infants. J Pediatr 1991, I 19:417-423.

14. Avery ME, Fletcher BD, Williams RG: The lung and its disorders in the newborn infant. Major Probl Clin Pediatr 198I, I 4th Edition: I-367.
15. Gluck L, Kulovich MV: Lecithin-sphingomyelin ratios in amniotic fluid in normal and abnormal pregnancy. Am J Obstet Gynecol 1973, I I 5:539-546.

16. Yoon J, Kohl S, Harper RG: The relationship between maternal hypertensive disease of pregnancy and the incidence of idiopathic respiratory distress syndrome. Pediatrics 1980, 65:735-739.

17. Schiff E, Friedman SA, Mercer BM, Sibai BM: Fetal lung maturity is not accelerated in preeclamptic pregnancies. Am J Obstet Gynecol 1993, 169:1096-I I0I.

18. Friedman SA, Schiff E, Kao L, Sibai BM: Neonatal outcome after preterm delivery for preeclampsia. Am J Obstet Gynecol 1995 , I72: I785-8; discussion I788-92.

19. Owen J, Baker SL, Hauth JC, Goldenberg RL, Davis RO, Copper RL: Is indicated or spontaneous preterm delivery more advantageous for the fetus? Am J Obstet Gynecol 1990, I 63:868-872.

20. Kramer MS, Olivier M, McLean FH, Willis DM, Usher RH: Impact of intrauterine growth retardation and body proportionality on fetal and neonatal outcome. Pediatrics 1990, 86:707-7I3.

21. Koops BL, Morgan LJ, Battaglia FC: Neonatal mortality risk in relation to birth weight and gestational age: update. J Pediatr 1982, I0 I:969-977.

22. Bernstein IM, Horbar JD, Badger GJ, Ohlsson A, Golan A: Morbidity and mortality among very-low-birth-weight neonates with intrauterine growth restriction. The Vermont Oxford Network. Am J Obstet Gynecol 2000, I 82:198-206.

23. Lal MK, Manktelow BN, Draper ES, Field DJ: Chronic lung disease of prematurity and intrauterine growth retardation: a population-based study. Pediatrics 2003, I I I:483-487.

24. Thompson PJ, Greenough A, Gamsu HR, Nicolaides KH: Ventilatory requirements for respiratory distress syndrome in small-for-gestational-age infants. Eur $J$ Pediatr 1992, | 5 |:528-53|.

25. Kulovich MV, Gluck L: The lung profile. II. Complicated pregnancy. Am J Obstet Gynecol 1979, I35:64-70.

26. Gross TL, Sokol RJ, Wilson MV, Kuhnert PM, Hirsch V: Amniotic fluid phosphatidylglycerol: a potentially useful predictor of intrauterine growth retardation. Am J Obstet Gynecol 198I, | 40:277-28I.

27. Nicolaides KH, Economides DL, Soothill PW: Blood gases, $\mathbf{p H}$, and lactate in appropriate- and small-for-gestational-age fetuses. Am J Obstet Gynecol 1989, 161:996-1001.

28. Regev RH, Lusky A, Dolfin T, Litmanovitz I, Arnon S, Reichman B: Excess mortality and morbidity among small-for-gestational-age premature infants: a population-based study. J Pediatr 2003, | 43: 186-191.

29. Reiss I, Landmann E, Heckmann M, Misselwitz B, Gortner L: Increased risk of bronchopulmonary dysplasia and increased mortality in very preterm infants being small for gestational age. Arch Gynecol Obstet 2003, 269:40-44.

30. Frank L, Sosenko IR: Undernutrition as a major contributing factor in the pathogenesis of bronchopulmonary dysplasia. Am Rev Respir Dis 1988, I 38:725-729.

31. Massaro GD, Massaro D: Formation of pulmonary alveoli and gas-exchange surface area: quantitation and regulation. Annu Rev Physiol 1996, 58:73-92.

32. Bartha JL, Romero-Carmona R, Comino-Delgado R: Inflammatory cytokines in intrauterine growth retardation. Acta Obstet Gynecol Scand 2003, 82:1099-I I02.

33. Hitti J, Krohn MA, Patton DL, Tarczy-Hornoch P, Hillier SL, Cassen EM, Eschenbach DA: Amniotic fluid tumor necrosis factoralpha and the risk of respiratory distress syndrome among preterm infants. Am J Obstet Gynecol 1997, I77:50-56.

34. Ersch J, Fauchere JC, Bucher HU, Hebisch G, Stallmach T: The pulmonary paradox in premature infants: in-utero infected lungs do better than those with accelerated maturation. J Perinat Med 2004, 32:84-89.

\section{Pre-publication history}

The pre-publication history for this paper can be accessed here:

http://www.biomedcentral.com/1471-2431/4/9/prepub 